\title{
A lower heel-bone ultrasound attenuation in middle- and older-aged women is associated with a higher urine sodium excretion and lower dietary calcium intake in the EPIC-Norfolk cohort
}

\author{
Ailsa Welch, Sheila Bingham and K. T. Khaw \\ University of Cambridge, Cambridge, UK
}

$\mathrm{Ca}$ is required for maintenance of bone density and a high salt intake is a risk factor for lower bone density because it induces calciuria ${ }^{(1)}$. As homeostatic mechanisms determine Ca absorption and excretion, it is possible that the detrimental effects of high salt intakes on bone may only occur when intakes of $\mathrm{Ca}$ are low. The relationship between urinary $\mathrm{Na}$ excretion, as a proxy for Na intake, and the interaction between dietary $\mathrm{Ca}$ intake and heel-bone ultrasound attenuation (BUA) was therefore investigated in middle- and older-aged women in the EPIC-Norfolk cohort.

Heel BUA was measured with a clinical contact ultrasound bone analyser CUBA clinical (McCue Ultrasonics, Winchester, Hants., UK) on the left and right foot at a health check and the average of the measurements used ${ }^{(2)}$. Casual urine samples were collected and frozen without preservation. $\mathrm{Na}$ and creatinine concentrations were measured $(\mathrm{mmol} / \mathrm{l})$ and $\mathrm{Na}$ : creatinine was calculated ${ }^{(3)}$. Dietary intake of Ca was calculated using the EPIC-Norfolk FFQ and divided into categories based on the UK and EC dietary reference values ${ }^{(4,5)}$. Mean heel BUA was calculated and adjusted for age, BMI, physical activity, smoking habit and hormone-replacement therapy (HRT) medication using ANOVA. Complete data for urine and BUA and dietary FFQ data were obtained for 7273 women aged 42-81 years.

Mean heel BUA was 72.1 (SD 16.5) dB/MHz, age 61.5 (SD 9.0) years, Na:creatinine 15.5 (SD 12.1) mmol:mmol and Ca 999 (SD $288) \mathrm{mg} / \mathrm{d}$. Heel BUA (dB/MHz) according to quartile (Q; based on mean ratio) of urine Na:creatinine (mmol:mmol) and dietary Ca intake were:

\begin{tabular}{|c|c|c|c|c|c|c|}
\hline \multirow[t]{2}{*}{$\begin{array}{l}\text { Dietary } \mathrm{Ca}(\mathrm{mg} / \mathrm{d}) \ldots . \\
n \ldots \ldots\end{array}$} & \multicolumn{2}{|c|}{$\begin{array}{l}<500 \\
212\end{array}$} & \multicolumn{2}{|c|}{$\begin{array}{c}500-799 \\
1601\end{array}$} & \multicolumn{2}{|c|}{$\begin{array}{l}\geq 800 \\
5460\end{array}$} \\
\hline & Mean & $\mathrm{SE}$ & Mean & $\overline{\mathrm{SE}}$ & Mean & SE \\
\hline Q1 (4.8) & 69.5 & 1.02 & 72.0 & 0.48 & 72.9 & 0.38 \\
\hline Q2 (9.3) & 68.5 & 1.01 & 71.1 & 0.49 & 71.9 & 0.38 \\
\hline Q3 (13.1) & 69.2 & 1.01 & 71.8 & 0.48 & 72.7 & 0.38 \\
\hline Q4 (18.0) & 68.7 & 1.01 & 71.2 & 0.48 & 72.1 & 0.38 \\
\hline Q5 (32.3) & 68.2 & 1.01 & 70.7 & 0.48 & 71.6 & 0.38 \\
\hline
\end{tabular}

Adjusted for age, BMI, physical activity, smoking habit and HRT medication.

Heel BUA was lower in women with higher $\mathrm{Na}$ excretion $(P=0.032$ for trend $)$ and was also lower in those women with a low Ca intake $(P<0.001$ for trend). There was an interaction between urine $\mathrm{Na}$ excretion and $\mathrm{Ca}$ intake $(P=0.0014)$ in the multivariate analysis. Those women in the highest category of $\mathrm{Ca}$ intake and lowest category of $\mathrm{Na}$ excretion had the highest BUA and those in the lowest category of $\mathrm{Ca}$ and highest category of $\mathrm{Na}$ had the lowest BUA, a difference of 4.7 units $\mathrm{dB} / \mathrm{MHz}$ or approximately $7 \%$.

The study found an inverse relationship between $\mathrm{Na}$ urine excretion and heel BUA in middle- and older-aged women, which was modified by dietary $\mathrm{Ca}$ intake. There was an approximately $7 \%$ difference between those with the highest excretion of Na and lowest intake of $\mathrm{Ca}$ and those with the lowest $\mathrm{Na}$ excretion and highest $\mathrm{Ca}$ intake, which remained after adjustment for osteoporotic risk factors. This relationship was found despite using casual urine samples and $\mathrm{Ca}$ intakes from FFQ, and given the likely measurement error the true relationship between the effects of $\mathrm{Na}$ and $\mathrm{Ca}$ intake on bone could be greater. Although a high $\mathrm{Na}$ excretion, reflecting high $\mathrm{Na}$ intake, significantly affects heel BUA, the interaction between $\mathrm{Na}$ and $\mathrm{Ca}$ intake appears to be important, and further studies are required to investigate the effects of $\mathrm{Na}$ intake on bone loss.

1. Rafferty K \& Heaney RP (2008) J Nutr 138, 166S-171S.

2. Welch A, Camus J, Dalzell N et al. (2004) Osteoporos Int 15, 217-225.

3. Khaw KT, Bingham S, Welch A et al. (2004) Am J Clin Nutr 80, 1397-1403.

4. Department of Health (1991) Dietary Reference Values for Food Energy and Nutrients for the United Kingdom. London: H. M. Stationery Office.

5. World Health Organization (2003) Prevention and Management of Osteoporosis. Geneva: WHO. 